\title{
Research of the Backfill Body Compaction Ratio Based on Upward Backfill Safety Mining of the Close-Distance Coal Seam Group
}

\author{
Xingping Lai $\mathbb{D}^{1,2}$ Leiming Zhang $\mathbb{D}^{1,2}$ Yun Zhang, ${ }^{1,2}$ Pengfei Shan, ${ }^{1,2}$ Peifeng Wan, ${ }^{1,2}$ \\ and Kaiwen $\mathrm{Mu}^{1,2}$ \\ ${ }^{1}$ School of Energy Engineering, Xi'an University of Science and Technology, Xi'an, Shaanxi 710054, China \\ ${ }^{2}$ Key Laboratory of Western Mines and Hazard Prevention, The Ministry of Education, Xi'an University of Science \& Technology, \\ Xi'an, Shaanxi 710054, China
}

Correspondence should be addressed to Leiming Zhang; zhangleiming@stu.xust.edu.cn

Received 7 January 2022; Accepted 16 February 2022; Published 7 March 2022

Academic Editor: Wen-long Shen

Copyright (C) 2022 Xingping Lai et al. This is an open access article distributed under the Creative Commons Attribution License, which permits unrestricted use, distribution, and reproduction in any medium, provided the original work is properly cited.

\begin{abstract}
During upward backfill mining of the close-distance coal seam group, the reasonable design of the backfill body compaction ratio (BBCR) of lower coal seam goaf plays a key role in controlling overburden strata movement and deformation. In this paper, the feasibility discrimination method of upward caving mining was adopted; it was found that when the coal seam spacing was small, the recovery was not possible due to the instability of the upper coal strata equilibrium structure caused by the mining. Hence, the upward backfill mining method was proposed; combined with the migration control mechanism of backfill mining overburden strata, the dynamic evolution of crack propagation height of overburden strata during upward backfill mining was analyzed. Based on that, a layer spacing-BBCR-mining height (L-R-H) prediction model based on multiple linear regression analysis was established and the BBCR of close-distance coal seam group safe upward mining was determined combined with the engineering background. The results demonstrate that the main controlling factors of crack propagation in overburden strata during upward backfill mining were BBCR and mining height; the crack propagation height in overburden strata caused by mining decreased exponentially with the increase of BBCR and increased with the increase of mining height linearly. The lower coal seam engineering safety BBCR of upward backfill mining in the Dafosi Coal Mine was 87.2\%, and the close-distance coal seam group safe upward mining was realized.
\end{abstract}

\section{Introduction}

Owing to exploitation of coal resources, coal resources with good occurrence conditions were increasingly scarce [1] and the mining of various complex coal seams has attracted great attention. Close-distance coal seams are widely distributed in China, and $92 \%$ of all large coal production bases are exposed to mining of close-distance coal seams (groups). Therefore, mining of the close-distance coal seam group has become a severe issue in recent years [2]. For the close-distance coal seam group, downward mining has some problems, such as difficult to form a hinged structure of the roof, instability of the roof structure, and air leakage; during upward caving mining, overburden strata movement and deformation caused by the mining of lower coal seams may influence the normal recovery of upper coal seams [3-5]. Additionally, in the process of coal mining, a large amount of gangues is discharged and accumulated to the surface, threatening the ecological environment of the mining area. Meanwhile, the construction of green mines [6-9] is constantly advocated by the government and relevant national and local policies have been issued for gangue discharge, calling for the backfilling of gangue to goaf. In this study, upward backfill mining is proposed to improve the coal recovery rate, reduce the damage range of overburden strata caused by lower mining, and reduce the emission of gangue, so as to provide an effective and feasible method to solve the above problems. 
Currently, great efforts have been invested in upward mining, backfill mining, and migration mechanism of overburden strata. For upward mining, Li and Qian [10] investigated the equilibrium structure of mining rock mass in upward mining and found that the key factors affecting the safety spacing of upward mining coal seams were the mining height, interlayer lithology, and structure of lower coal seams. Additionally, the upward mining discriminant formula for the rock mass without a hard interlayer was proposed. Shi and Mo [11] analyzed the stress environment of upper coal seams during upward mining of close-distance coal seams by RFPA, and combined with field monitoring, it was concluded that upward mining had a more obvious maintenance effect on the stability of the upper coal seam roadway. Ma et al. [12] considered the relationship between the overburden strata condition of upper coal seams and upward mining; the results revealed that the key of upward mining was to analyze and control the longitudinal step dislocation of the coal (rock) layer. Feng et al. [13] proposed that the key technology in upward mining was rock stratum control. Based on considering the structure of key layers of the upward mining interlayer rock stratum, the specific judgment method of key position of upward mining interlayer rock stratum control was explored by vector analysis method. Zhang et al. [14] studied the migration and failure characteristics of upper coal seams under different first mining heights through theoretical analysis and numerical simulation and further designed the first mining sequence, i.e., mining mode of on-site mining. Wang et al. [15] investigated the structural form of the roof and floor under repeated upward mining by theoretical analysis and similar simulation and proposed the "upward mining three hinged arch structure," and the stability condition criterion based on the proposed mechanical model was obtained. On the research of backfill mining, Miao [16] established the equivalent mining height method for strata movement control and surface subsidence prediction of solid backfill mining, which has been successfully applied to actual engineering. Combined with the key layer theory, Zhang et al. [17] investigated the relationship between the maximum deflection and strength of the key layer, the elastic foundation coefficient of the lower stratum and the lithologic parameters, and proposed the backfill mining surface subsidence control principle to limit the subsidence of the key layer. Deng et al. [18] studied the whole process dynamic subsidence curve of the upper coal seam roof with the progress of lower coal seam backfill mining and expounded the influence of elastic model and strength variation of the filler on the upper coal seam roof subsidence. Zhou et al. [19] evaluated the filling effect of solid backfill mining goaf with BBCR as the measurement index and studied the key factors affecting BBCR, and the BBCR monitoring system was established according to the engineering practice in order to optimize the backfill mining technique. Nevertheless, for the problem of closedistance coal seam group upward backfill mining, domestic and foreign researchers have made sufficient research and explanation on the criterion, failure mechanism, filling principle, and method of upward mining, but due to the particularity of upward backfill mining, compared with single coal seam backfill mining, BBCR had a more important impact on controlling overburden strata failure. To date, there rarely were researches on the design of BBCR in upward backfill mining; it was urgent to carry out further research and exploration.

In this study, the geological conditions of the Dafosi Coal Mine were regarded as the research background; based on the analysis of the migration law and failure mechanisms of overburden strata during upward backfill mining of the close-distance coal seam group, the main controlling factors affecting overburden strata were determined. Through the study of dynamic evolution law of the crack propagation height of overburden strata during upward backfill mining of the close-distance coal seam group, the prediction model of L-R-H was obtained by multivariate nonlinear regression analysis, the safety coefficient of the project was selected according to the project site, and finally, the engineering safety BBCR of the upward backfill mining of the closedistance coal seam group was obtained; the research path was shown in Figure 1. The results are of great significance to the supplement of the BBCR design method of the upward backfill mining of the close-distance coal seam group, the full exploitation and utilization of coal resources, and the construction of green and safe mines.

\section{Engineering Context}

The Dafosi Coal Mine is located in the south of the Binchang mining area, Binzhou city, Shaanxi province. The stratum of the mining area tilts from southeast to northwest, and the mining field trend is close to east-west and generally tilts north. The mine field area is $86.3 \mathrm{~km}^{2}$ and the design production capacity is 6 million tons per year. There are two main minable coal seams, 4 coal and 4 upper coal. The dip angle of coal bearing strata is generally $3 \sim 5$; the mine field geological is simple. The average thickness of coal seam 4 is $11.41 \mathrm{~m}$, the dirt band layer thickness is $0.1 \sim 0.3 \mathrm{~m}$, and the buried depth is about $552.81 \mathrm{~m}$. Upper coal seam 4 is above coal seam 4 , the dirt band layer thickness is $0.1 \sim 0.6 \mathrm{~m}$, the average coal thickness is $2.95 \mathrm{~m}$, and the buried depth is about $520.95 \mathrm{~m}$. Between the two coal seams, the finegrained sandstone, siltstone, and mud layers were distributed interactively from top to bottom with a spacing of $20.45 \mathrm{~m}$, which belongs to close-distance coal seams. The comprehensive histogram of coal seam lithology between the average working face coal seam of the main coal seam is measured by borehole D33 (Figure 2).

In order to improve economic benefits and recover the initial cost of well construction as soon as possible, the 401 mining area of coal seam 4 is the first mining face of the Dafosi Coal Mine. The gangue layer in this coal seam is thick, and a large amount of gangues will be generated in the mining process. At the same time, due to the small coal seam spacing, the traditional upward mining method of coal seam 4 is easy to induce roof caving accidents, resulting in the movement of overburden strata and deformation. The normal mining in the later stage of upper coal seam 4 cannot be guaranteed. Therefore, in view of these problems, current mining methods are proposed to be improved. 


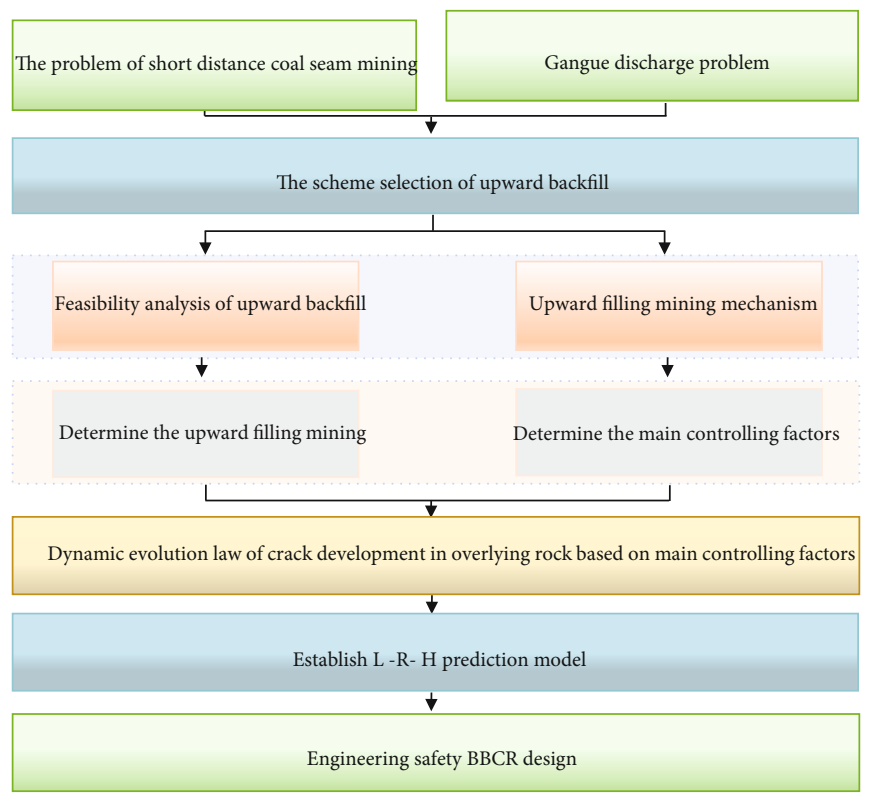

Figure 1: Schematic diagram of the research path.

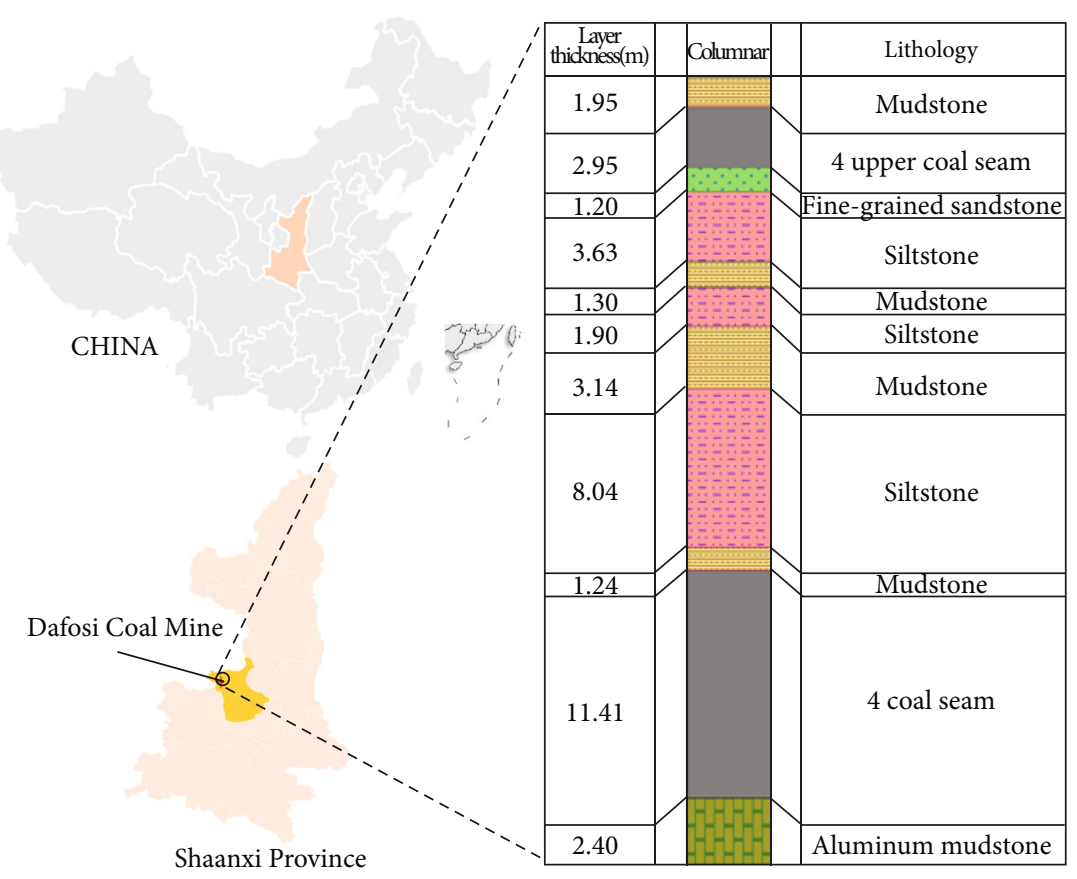

FIGURE 2: Local coal seam comprehensive histogram of the Dafosi Coal Mine.

\section{The Scheme Selection of Upward Backfill}

3.1. Feasibility Analysis of Upward Backfill. The key to the upward mining feasibility is that the upper coal seams are located on the equilibrium rock stratum which is closest to the lower coal seams. The ratio discrimination method, "three zone" discrimination method, surrounding rock equilibrium method, and mathematical statistics method were selected for discrimination and calculation [14, 20]. The four traditional collapse upward mining feasibility methods were shown in Table 1.
As observed, method I was the ratio discrimination method, method II was the "three-zone" discrimination method, method III was the surrounding rock equilibrium method, and method IV was the mathematical statistics method; $H$ was the coal seam spacing, $20.45 \mathrm{~m}$; $M$ was the lower coal seam mining height, $11.41 \mathrm{~m} ; K_{0}$ was the dilatancy coefficient of caving rock, taken as $1.3 ; A$ was the dip angle of coal seam, $3^{\circ} ; K_{a}$ was the dilatancy coefficient of rock, taken as 1.3 ; $h$ was the thickness of the equilibrium rock stratum, $8.24 \mathrm{~m} ; M_{L}$ was the upper coal seam mining height, $2.95 \mathrm{~m}$. 
TABLE 1: Method for judging the feasibility of upward backfill.

\begin{tabular}{lccccc}
\hline Method & Formula & Variable & Meaning & $\begin{array}{c}\text { Literature } \\
\text { source }\end{array}$ & Comparison index \\
\hline I & $K_{Z}=H / M$ & $K_{Z}$ & $\begin{array}{c}\text { The ratio of the distance between the upper and lower } \\
\text { coal seams to the thickness of the lower coal seam }\end{array}$ & $K_{Z}>7.5$ \\
II & $H_{M}=M /\left(K_{0}-1\right) \cos A$ & $H_{M}$ & Height of the caving zone & $\begin{array}{c}\text { Zhang }[14], \\
\text { Xu }[20]\end{array}$ & $H<20.45$ \\
III & $H>\left(M / K_{a}-1\right)+h$ & $H$ & Seam spacing necessary for upward mining & $H<20.45$ \\
IV & $H>1.14 M^{2}+4.14+M_{L}$ & $H$ & Seam spacing necessary for upward mining & $H$ \\
\hline
\end{tabular}

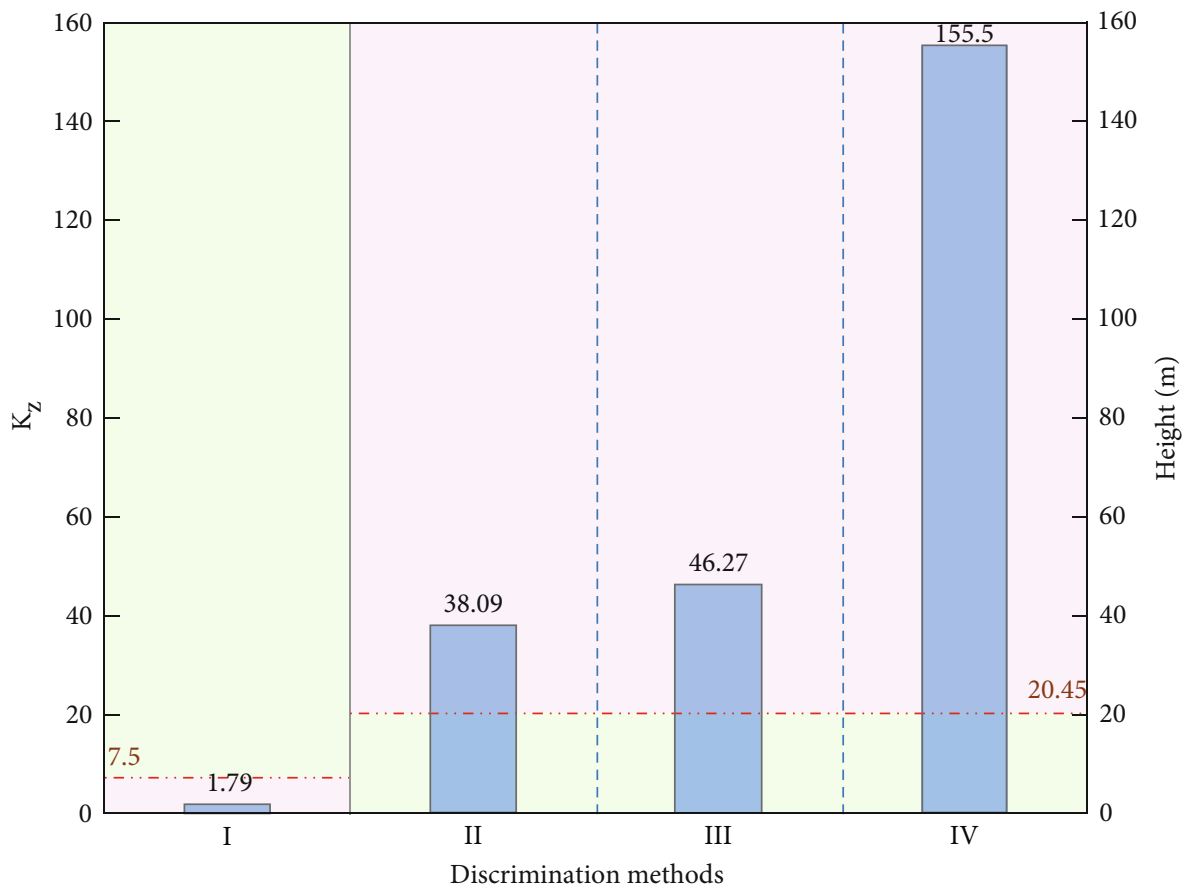

Calculated

Discriminant value

FIgURE 3: Comparison chart of discriminant method results.

By substituting relevant parameters into the calculation formula of each feasibility method in Table 1, the traditional collapse upward mining feasibility discriminations were finally obtained and shown in Figure 3. The calculation results of the four kinds of discriminations were 1.79, $38.09,46.27$, and $155.5 \mathrm{~m}$. Since the distance between coal seam 4 and upper coal seam 4 of the Dafosi Coal Mine was small and the lower coal seams were extra thick coal seams, if the traditional caving mining method was used to mine the 4 coal, the overburden strata of coal seam 4 would be damaged in a large scale; the structural integrity of upper coal seam 4 would be damaged, resulting in the failure of normal mining of the upper coal seams and a serious waste of resources. Therefore, it was proposed that the upward backfill mining was carried out on the 4 coal in order to mitigate the gangue issue and reduce the overburden strata movement and deformation.

3.2. The Mechanism of Backfill Upward Mining. During mining of close-distance coal seam groups by upward mining sequential caving, with the mining of lower coal seams, the equilibrium stress state of the stope overburden strata was changed and the horizontal stress and vertical stress of the rock mass would be redistributed until the equilibrium state. When the redistributed stress reached the failure strength of the rock mass, a large number of mining fissures would be produced in the horizontal and vertical directions of overburden strata of the stope and it would experience the deformation and failure stages of "regional fissure-compaction closure-overall bench dislocation." Meanwhile, the bending deformation would form the changes of the "horizontal three zone" and "vertical three belt." When the upper coal seams were located in the area affected by the collapse zone or the fracture zone, severe bench dislocation would occur; the structure would be no longer be whole in a large area, which seriously affected the layout of the upper coal seam workface, resulting in the failure of normal mining of upper coal seams (Figure 4). Unlike the conventional upward caving method, in upward backfill mining, gangues were filled into goaf timely after coal mining $[21,22]$ and compaction 


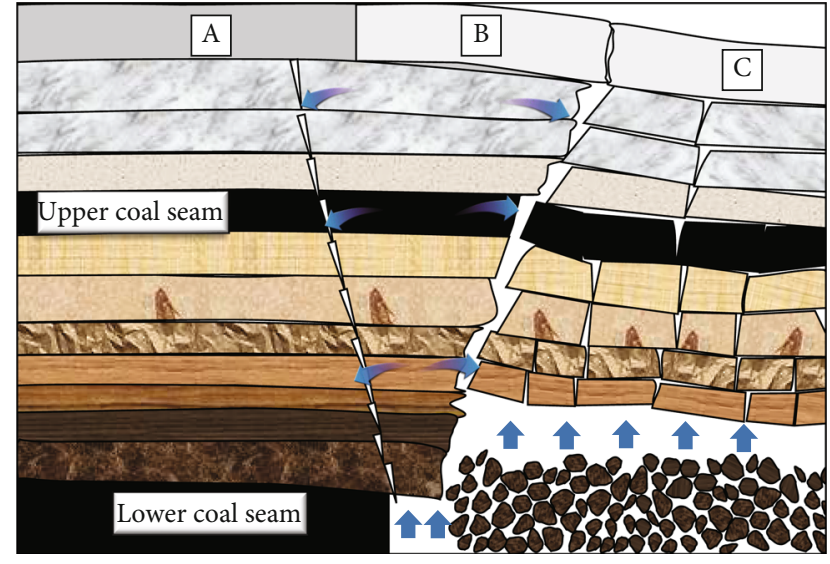

FIGURE 4: Movement state of overlying rock in the stope of caving method.

treatment was followed; the direct roof was effectively supported by the filler. During the advancement of the workface, the vertical stress of the overburden strata was acted on the filler continuously, the original pores of the gangue filler were compacted gradually, and the roof sunk slowly. After the filler was compacted to a certain extent, the bending subsidence of the overlying roof was slowed down, and the overburden strata of goaf was effectively controlled, there would be no step dislocation and only the fracture zone and bending subsidence zone would be formed above overburden strata (Figure 5). Under the control of filler, overburden strata were effectively supported and the caving space was filled, which was equivalent to reducing the mining height that greatly reduced the failure range of overburden strata under the influence of mining, so as to effectively ensure the integrity of upper coal seams and realize the purpose of normal mining of upper coal seams finally.

\subsection{Determination of Main Controlling Factors of Overlying} Rock Cracks in Upward Backfilling Mining. According to the particularity of upward backfill mining and the migration mechanism of overburden strata, the main factors affecting crack propagation in overburden strata during upward backfill mining were mining height, BBCR, buried depth, and interlayer lithology but the buried depth and interlayer lithology were original geological parameters, which could not be changed. Therefore, the main controlling factors affecting crack propagation in overburden strata during upward backfill mining were as follows:

3.3.1. Mining Height. According to the previous research experience and the upward mining discrimination method, there was a direct relationship between the workface mining height and the migration law of overburden strata. With different mining height in the workface mining, the development heights of the "three zone" of overburden strata in the corresponding stope were different [23-25] and there were significant differences in the equilibrium structure and damage degree of overburden strata. Meanwhile, according to the caving height and crack propagation height calculation formulas [26] in the code for coal pillar retention and coal mining in buildings, water, railways, and main roadways, the relationships between caving height, crack propagation height, and mining height were unique and the two factors were vital to the upward mining discrimination. Therefore, it could be determined that mining height was one of the main controlling factors affecting upward backfill mining.

3.3.2. BBCR. According to the above upward backfill mining mechanism, the filling of the filler was equivalent to changing the mining height and the change of $\mathrm{BBCR}$ also changed the equivalent mining height. Therefore, the filler BBCR was directly related to the controlling effect of overburden strata; the BBCR within a reasonable range could ensure the normal mining of upper coal seams.

Therefore, it could be determined that under certain geological conditions, the key points to realize upward backfill mining were to design reasonable BBCR and mining height to carry out backfill mining of lower coal seams and control the deformation and failure of overburden strata and the stable rock structure which could ensure the normal mining of upper coal seams.

\section{Dynamic Evolution Law of Crack Development in Overlying Rock Based on Main Controlling Factors}

4.1. Numerical Calculation Model Establishment. According to the geological survey report of the Dafosi Coal Mine in the Binchang mining area, Shaanxi province, a FLAC ${ }^{3 \mathrm{D}}$ threedimensional numerical model was established. As shown in Figure 6, the model and workface sizes were $500 \mathrm{~m} \times 480 \mathrm{~m}$ $\times 180 \mathrm{~m}(\mathrm{~L} \times \mathrm{W} \times \mathrm{H})$ and $220 \mathrm{~m} \times 380 \mathrm{~m}(\mathrm{~L} \times \mathrm{W})$, respectively. The model consisted 179358 nodes and 178000 elements; the thickness of reserved coal pillars in the front-back boundary was $50 \mathrm{~m}$, in which the left-right boundary was $140 \mathrm{~m}$. According to the concept of in situ stress, a uniformly distributed load of $9.9 \mathrm{MPa}$ was applied to the upper boundary of the model (unit weight $=2.5 \mathrm{kN} / \mathrm{m}^{3}$, buried depth $=396 \mathrm{~m}$ ). The upper surface was the free surface, and displacement constraints were applied on other surfaces. The MohrCoulomb strength criterion was adopted, and the physical and mechanical parameters of coal rock mass in the model were based on the test results of coal rock samples in the laboratory, as shown in Table 2.

The specific scheme of numerical simulation was as follows: the mining height was set as $11.41 \mathrm{~m}$, and the crack propagation in overburden strata with goaf BBCR of 0 , $40 \%, 60 \%, 70 \%, 75 \%, 80 \%$, and $85 \%$ was simulated, respectively. According to the previous research experience, the goaf BBCR was set as $80 \%$ and the crack propagation in overburden strata with workface heights of $3,5,7,9$, and $11 \mathrm{~m}$ was simulated, respectively (see Table 3 ).

\subsection{Analysis of Numerical Simulation Results}

4.2.1. Crack Propagation Situation of Overburden Strata under BBCR Control. Based on the upward backfill mining of coal seam 4 in the Dafosi Coal Mine, seven groups of simulation studies of tests I-1 I-7 in Table 3 were carried out 


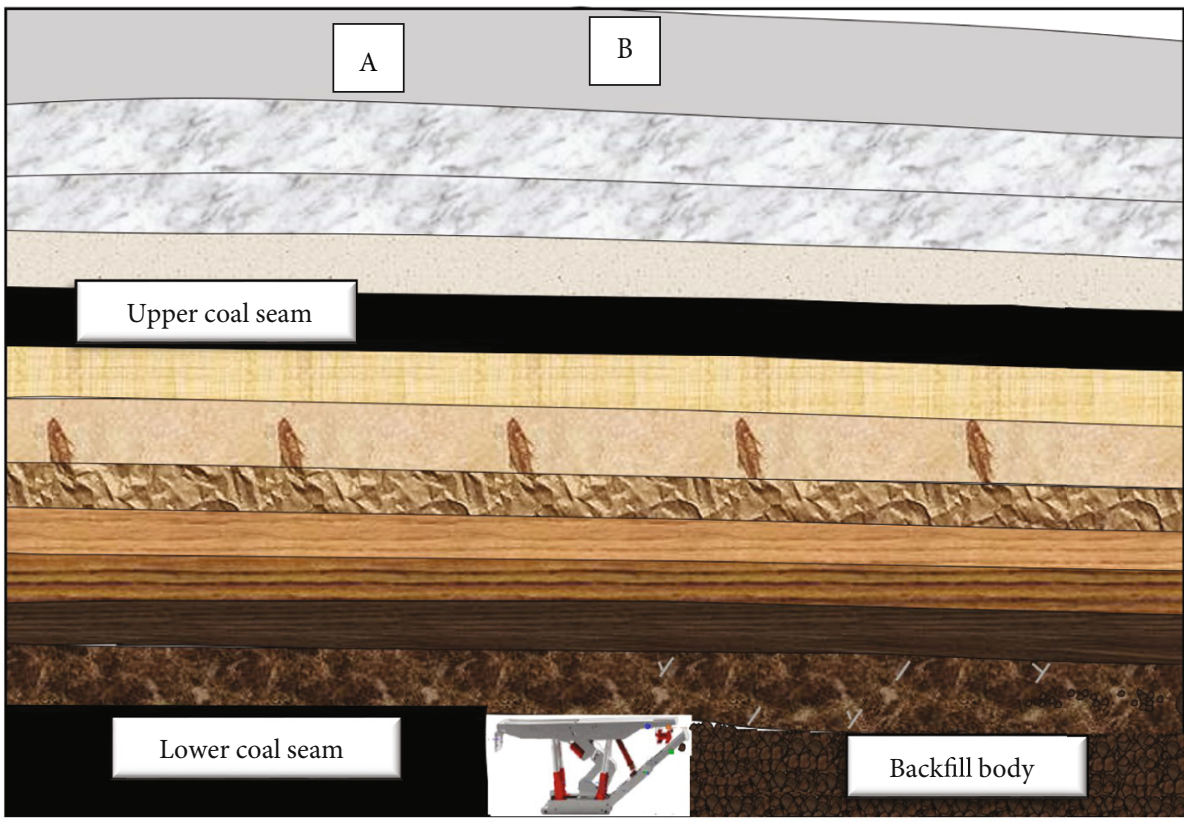

FIgURE 5: Movement state of overlying rock in the stope of backfilling method.

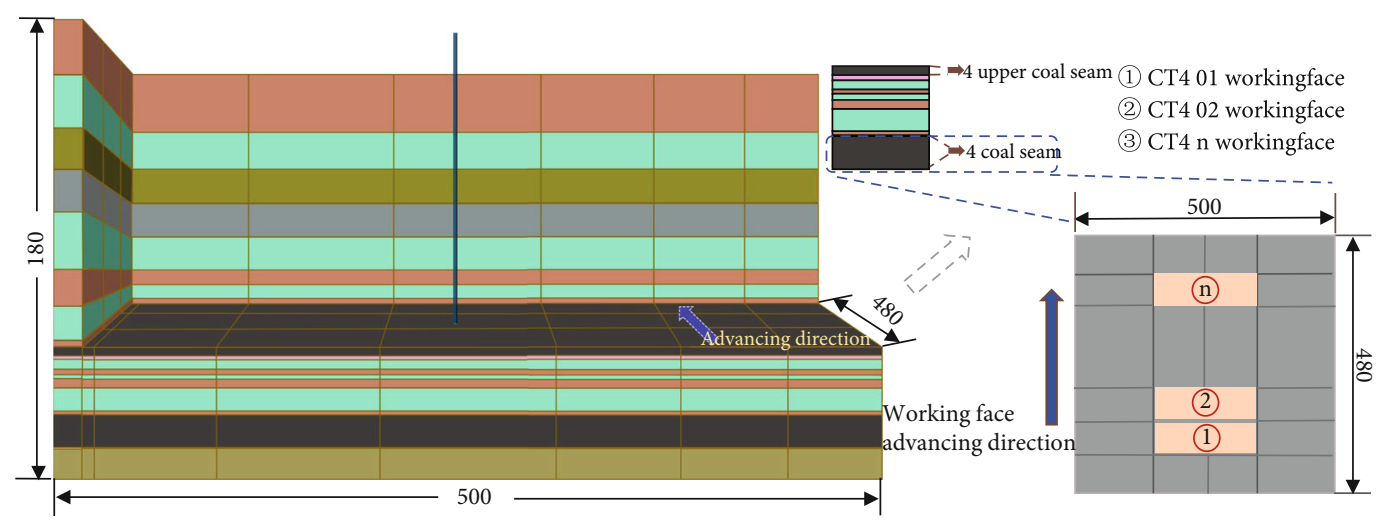

Figure 6: Numerical model diagram of the Dafosi Coal Mine (m).

TABLE 2: The detailed physical and mechanical parameters.

\begin{tabular}{|c|c|c|c|c|c|c|c|}
\hline Serial number & Lithology & $\begin{array}{l}\text { Bulk modulus } \\
\qquad(\mathrm{GPa})\end{array}$ & $\begin{array}{l}\text { Shear modulus } \\
(\mathrm{GPa})\end{array}$ & Density $\left(\mathrm{g} / \mathrm{cm}^{3}\right)$ & $\begin{array}{c}\text { Cohesion } \\
(\mathrm{MPa})\end{array}$ & $\begin{array}{c}\text { Tensile strength } \\
(\mathrm{MPa})\end{array}$ & $\begin{array}{l}\text { Friction } \\
\text { angle }\left({ }^{\circ}\right)\end{array}$ \\
\hline 1 & Gravelly coarse sandstone & 12.04 & 5.32 & 2.85 & 4.61 & 4.35 & 42.3 \\
\hline 2 & Sandy mudstone & 6.83 & 2.89 & 2.73 & 3.34 & 1.86 & 34.8 \\
\hline 3 & Siltstone & 8.82 & 4.84 & 2.65 & 3.20 & 2.47 & 37.3 \\
\hline 4 & Fine-grained sandstone & 7.87 & 3.34 & 2.63 & 3.65 & 2.19 & 37.1 \\
\hline 5 & 4 coal, 4 upper coal & 2.35 & 1.42 & 1.33 & 2.99 & 1.10 & 36.2 \\
\hline 6 & Mudstone & 3.64 & 2.10 & 2.36 & 3.20 & 1.50 & 34.8 \\
\hline 7 & Aluminum mudstone & 1.68 & 1.14 & 2.56 & 5.20 & 1.10 & 33.8 \\
\hline
\end{tabular}


TABLE 3: Numerical simulation scs.

\begin{tabular}{lcc}
\hline Test number & Mining height $(\mathrm{m})$ & BBCR $(\%)$ \\
\hline I-1-I-7 & 11.41 & $0 ; 40 ; 60 ; 70 ; 75 ; 80 ; 85$ \\
II-1-II-5 & $3 ; 5 ; 7 ; 9 ; 11$ & 80 \\
\hline
\end{tabular}

and the goaf BBCR and crack propagation height of overburden strata of coal seam 4 were analyzed and shown in Figure 7. As observed, the crack propagation height of overburden strata decreased exponentially with the increase of $\mathrm{BBCR}$, with the continuous increase of the filling rate, the reduction rate of propagation height of overburden strata decreased gradually, and the variation process was mainly divided into two stages: sharp reduction (BBCR: 0 60\%) and slow reduction (BBCR: 60\% 85\%); with the increase of $\mathrm{BBCR}$, the overall variation range of floor crack propagation depth was small and the variation rate was small. With the decrease of the influence range of floor cracks, the bearing capacity of the floor under the force of the filler was improved. When $\mathrm{BBCR}=0$, the roof and floor of traditional caving coal seam first experienced shear failure, and then, the tensile fracture and caving occurred under the action of biaxial tensile stress. Finally, the goaf roof fracture further expanded to complete failure, overburden strata were damaged and migrated, the rock stratum became unstable, the corresponding crack propagation height of overburden strata in the simulation was about $71 \mathrm{~m}$, the potential damage range was large, the upper coal seams were involved, the damage was obvious, and the normal mining could not be carried out. When $\mathrm{BBCR}=40 \%, 60 \%, 70 \%$, and $75 \%$, the influence range of the overburden strata fracture was significantly reduced compared with that before but the upper coal seam was still within the damage range; the normal mining could not be carried out. When the filling rate was $80 \%$ and $85 \%$, the influence range of the overburden strata fracture decreased below the upper coal seams, the degree of fracture migration of overburden strata decreased sharply, and the upper coal seams could be mined normally.

Nonlinear regression analysis was carried out for the crack propagation height of overburden strata and BBCR obtained from the simulation research of upward backfill mining; the dynamic evolution laws of BBCR in Figure 7 and crack propagation height of overburden strata were obtained as follows:

$$
\begin{aligned}
& H_{S}=-14.244+85.385 \times 0.988^{\varphi}, \\
& R^{2}=0.998,
\end{aligned}
$$

where $H_{S}$ refers to the crack propagation height of overburden strata, $\mathrm{m} ; \varphi$ is the BBCR, \%; and $R$ is the correlation coefficient.

4.2.2. Crack Propagation Situation of Overburden Strata under Different Mining Height Conditions. According to the established numerical model, the simulation study of II-1 II-5 in Table 3 was carried out in which BBCR was set as $80 \%$ and the mining height was varied; the relationship between different the mining height and crack propagation height of overburden strata in coal seam 4 was analyzed and shown in Figure 8. The crack propagation height of overburden strata increased with the increase of mining height, and the failure range of overburden strata and the floor increased as well. When the mining height increased from $3 \mathrm{~m}$ to $11 \mathrm{~m}$, the overburden strata fracture increased from $10.9 \mathrm{~m}$ to $19.2 \mathrm{~m}$ and the crack propagation depth of the coal seam floor increased from $2.9 \mathrm{~m}$ to $4.6 \mathrm{~m}$. With the increase of mining height, the damage degree of overburden strata in the coal seam was gradually increasing. Therefore, it could be seen that the increase of mining height promoted the development of overburden strata fractures.

As shown in Figure 8, the crack propagation height of overburden strata-mining height curve was approximately a monotonically increasing straight line. Through the linear regression analysis of the law between crack propagation height of overburden strata and mining height, it could be seen that when the BBCR was $80 \%$, the mining height and crack propagation height of overburden strata could be described by

$$
\begin{aligned}
H_{S} & =7.99+1.03 M, \\
R^{2} & =0.993 .
\end{aligned}
$$

\section{L-R-H Prediction Model Based on Multivariate Nonlinear Regression Analysis}

5.1. Multiple Nonlinear Regression Analysis Method. Based on the two dynamic evolution laws of BBCR-crack propagation height of overburden strata and mining height-crack propagation height of overburden strata obtained from numerical simulation, a multivariate nonlinear regression model was established. The basic model could be established as follows:

$$
y=\beta_{1} 0.988^{x_{1}}+\beta_{2} x_{2}+\beta_{0},
$$

where set $x_{1}^{\prime}=0.988^{x_{1}}, x_{2}^{\prime}=x_{2}$; then, the nonlinear region model in equation (9) could be converted into a linear regression model for calculation:

$$
y=\beta_{1} x_{1}^{\prime}+\beta_{2} x_{2}^{\prime}+\beta_{0} .
$$

The least square method was selected to solve the regression coefficient $\beta_{0}, \beta_{1}$, and $\beta_{2}$, the specific solution process was as follows:

$$
f\left(x_{i}^{\prime}\right)=\sum\left(y_{i}-\widehat{y}_{i}\right)=\sum\left(y_{i}-\beta_{0}-\beta_{1} x_{1 i}^{\prime}-\beta_{2} x_{2 i}^{\prime}\right)^{2}=\min ,
$$

where the dependent variable was, the independent variables were $x_{1 i}^{\prime}, x_{2 i}^{\prime}$; both were known as observation values. Then, 


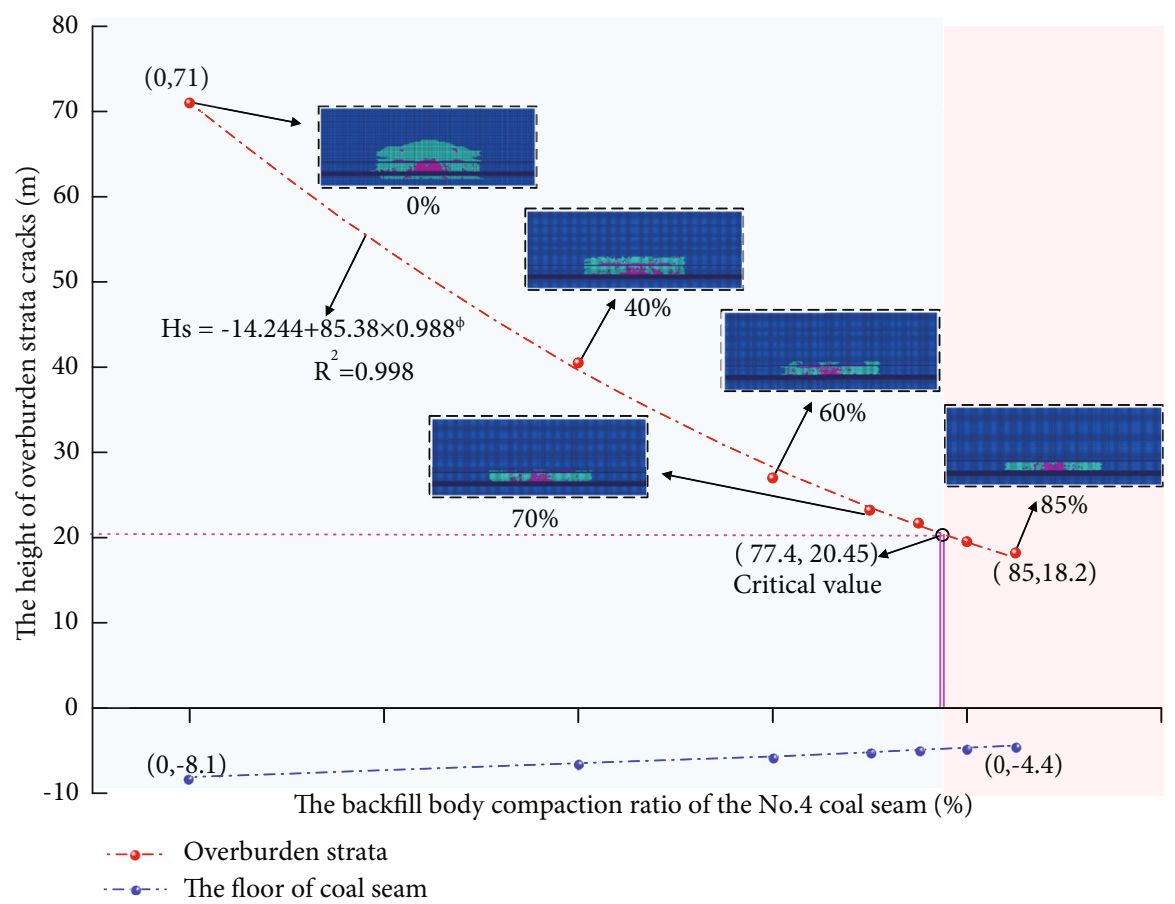

FIGURE 7: Relationship between different BBCR of 4 coal seam goaf and crack propagation height of overburden strata.

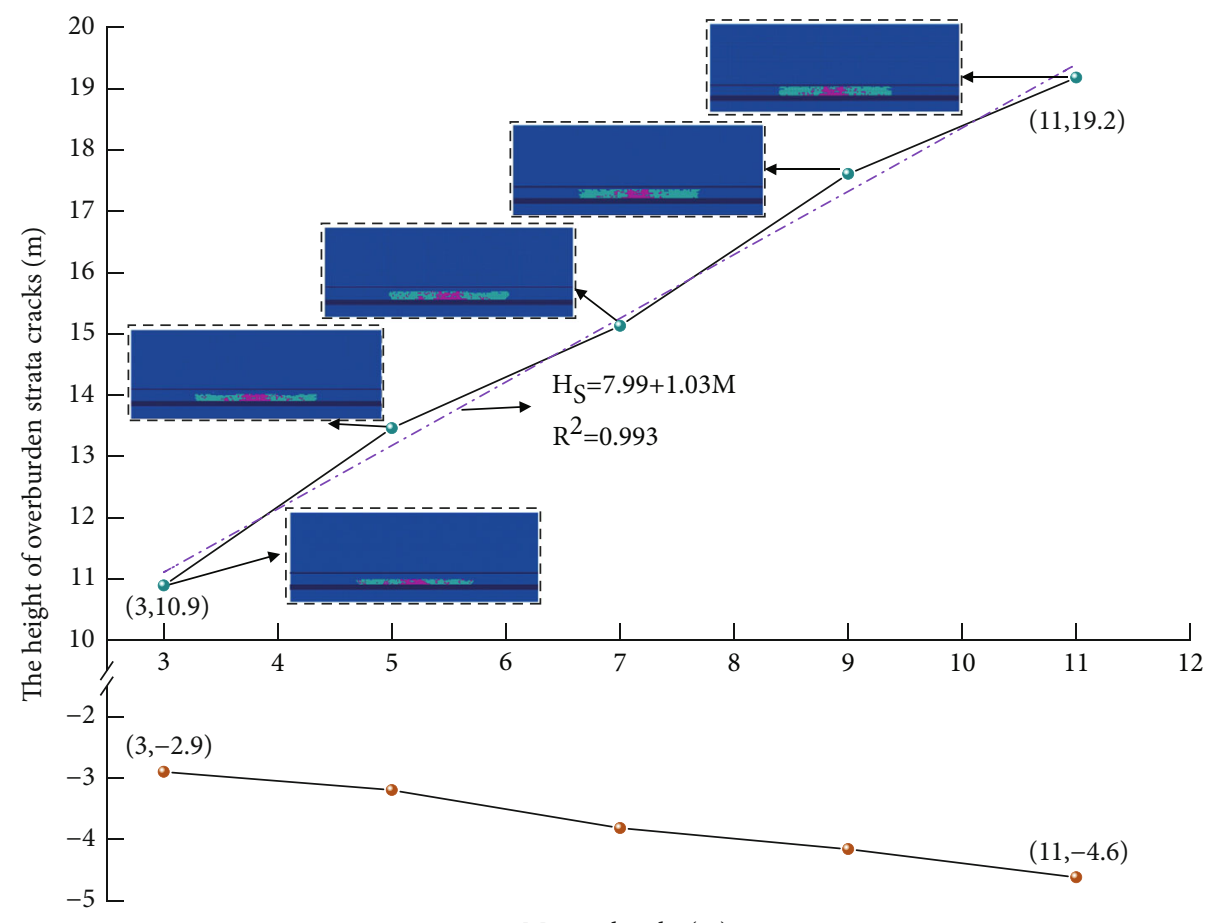

Mining height (m)

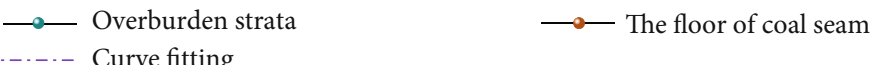

FIGURE 8: Relationship between different mining heights of 4 coal seam and crack propagation height of overburden strata. 


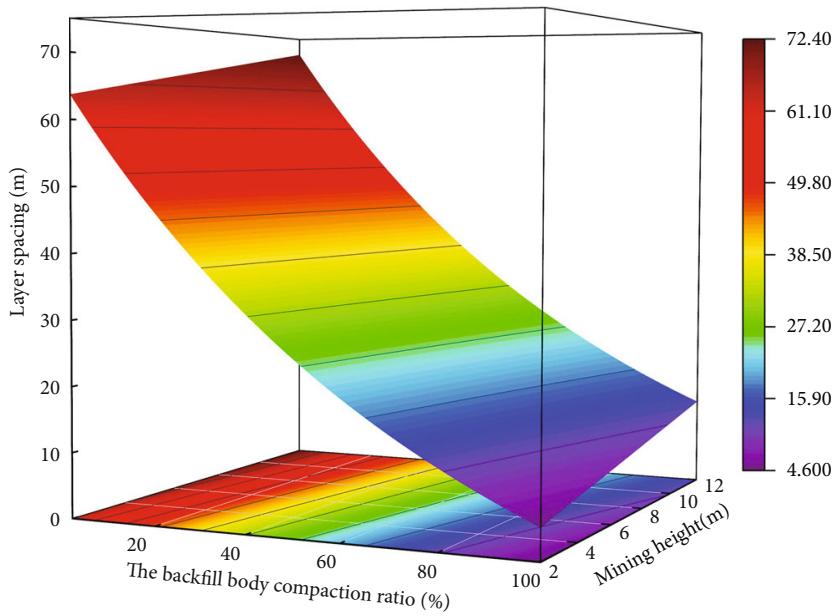

Figure 9: "L-R-H” prediction model function analytic curve.

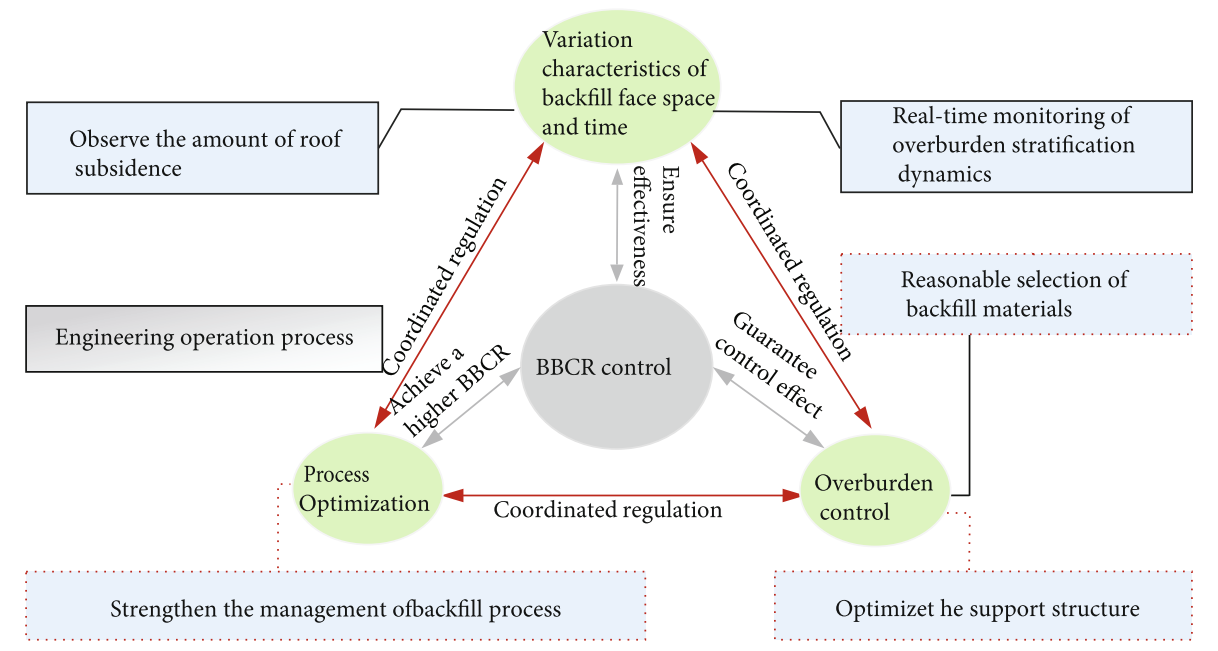

FIGURE 10: The regulation mechanism of BBCR.

the derivation of $\beta_{0}, \beta_{1}$, and $\beta_{2}$ was carried out and the reciprocal of the first-order derivation was treated as zero; the regression coefficients were calculated as follows:

$$
\begin{aligned}
& J_{11} \beta_{1}+J_{12} \beta_{2}=J_{1 y} \\
& J_{21} \beta_{1}+J_{22} \beta_{2}=J_{2 y},
\end{aligned}
$$

where

$$
\begin{aligned}
& J_{i j}=J_{j i}=\sum\left(x_{i j}^{\prime}-\bar{x}_{i}^{\prime}\right)\left(x_{i j}^{\prime}-\bar{x}_{j}^{\prime}\right), \\
& J_{i y}=\sum\left(x_{i j}^{\prime}-\bar{x}_{i}^{\prime}\right)\left(y_{i}-\bar{y}_{i}\right),
\end{aligned}
$$

where $J_{i 1}, J_{i 2}(i=1,2)$ were known, i.e., $x_{i j}^{\prime}, \overline{x^{\prime}}{ }_{i}, y_{j}, \bar{y}(i=1,2)$ were known; the determinant method or elimination method was used to solve the correlation equations of $\beta_{1}$, $\beta_{2}$, and $\beta_{0}$ which could also be obtained by further solving.

The standard multiple correlation coefficient $R$ reflecting the fitting quality was selected to measure the reasonability of the regression equation, which was $\left[R^{2}(y, 1,2)=\sum\right.$ $\left.\left(\widehat{y}_{i}-\bar{y}\right)^{2} / \sum\left(y_{i}-\bar{y}\right)^{2}\right]$. This statistic was an important index to evaluate the quality of the regression model; the greater the $R^{2}(\approx 1)$, the stronger the linear relationship between $y$ and $x_{1}^{\prime}, x_{2}^{\prime}$ and the better the fitted regression equation.

5.2. The Establishment of the L-R-H Prediction Model. Based on the above nonlinear regression basic model, MATLAB software was used to conduct multivariate nonlinear regression analysis on the relationship between two main controlling factors (goaf BBCR and workface mining height) and crack propagation height of overburden strata; the L-R-H prediction model was obtained as follows:

$$
H_{S}=85.6 \times 0.988^{\varphi}+0.85 M-22.53 .
$$

After the calculation of the correlation degree of the regression equation, the square value of the multivariate correlation coefficient $R^{2}=0.984$, indicating a sound prediction effect of the model, and the analytic curves were shown in Figure 9. 


\section{Engineering Design}

6.1. Selection of the Engineering Safety BBCR. According to the actual geological data and production conditions of the Dafosi Coal Mine, the distance between the roof of coal seam 4 and the floor of upper coal seam 4 was $20.45 \mathrm{~m}$. Meanwhile, the coal yield rate should be increased as much as possible in the production process to maximize the benefit. Therefore, $11.41 \mathrm{~m}$ was selected as the maximum mining height and substituted into the prediction model; the obtained critical value was $78.3 \%$. Considering the engineering requirements of safe mining, it was necessary to determine the safety coefficient to ensure the layer spacing within the safety threshold. The safety layer spacing should meet the requirements:

$$
N H \leq H_{S}
$$

where $N$ is the safety factor; choose 1.2 .

Through calculation, the interval should be more than $17.04 \mathrm{~m}$. On the basis that the mining height and the interval of coal seams within the safety threshold were determined, the engineering safety BBCR could be calculated by equation (8):

$$
17.04=85.6 \times 0.988^{\varphi}+0.85 \times 11.41-22.53 .
$$

Therefore, in the process of safe upward backfill mining, the engineering safety BBCR applied in the site was $87.2 \%$.

6.2. The Control Measures of BBCR. In the actual engineering operation, the filler should be reasonably selected and support structures should be optimized to ensure the control effect of overburden strata after filling. The elastic-plastic performance and ratio of the filler should meet the actual demand, while the support structure should provide sufficient initial support force; the steel mesh supported was provided according to the roof situation. The backfill mining $\mathrm{BBCR}$ value was ensured by strengthening the management of the filling process, ensuring the rationality of mining and filling cycle sequence, the timeliness of roof support, and the reliability of compaction operation; the roof sinker, multipoint displacement meter, and other monitoring measures to dynamically observe the roof sinkage and overburden strata separation in time, the space and time variation characteristics were investigated to determine the accommodation ratio of solid filler and timely feedback the effectiveness of engineering safety BBCR. monitoring equipment is used to observe the spatial and temporal variation characteristics of the filling face in real time. In order to determine the holding ratio of solid filling materials, timely feedback the effectiveness of engineering safety BBCR. The regulation mechanism of BBCR was shown in Figure 10, and the control measures of BBCR were implemented to ensure the filling of lower coal seam goaf and the safe mining of upper coal seams after reasonable residence time.

\section{Conclusion}

(1) Through the theoretical research and calculation of the ratio discrimination method, "three zone" discrimination method, surrounding rock equilibrium method, and mathematical statistics, it was found that, after the traditional upward mining of \#4 coal in the Dafosi Coal Mine, the overburden strata of coal seam 4 was damaged in a large range and upper coal seam 4 was within the damage range and could not be recovered

(2) By analyzing the mechanism of upward backfill mining of the close-distance coal seam group, it was concluded that there would not be severe bench subsidence for overburden strata during upward backfill mining; the integrity of upper coal seams was guaranteed and could be mined normally. The BBCR and mining height were determined to be the main controlling factors of upward backfill mining

(3) The crack propagation height of overburden strata increases exponentially and linearly with BBCR and mining height, respectively. Based on that, the L-R$\mathrm{H}$ prediction model was obtained through nonlinear regression analysis with MATLAB

(4) According to the prediction model, the critical BBCR for upward backfill mining was $78.3 \%$. The safety coefficient was introduced considering the threshold of safety mining; the engineering safety BBCR which was satisfied with the requirements of safety production was determined to be $87.2 \%$ finally

\section{Data Availability}

The experimental data used to support the findings of this study are included within the article.

\section{Conflicts of Interest}

The authors declare that they have no conflicts of interest.

\section{Acknowledgments}

We thank the National Natural Science Foundation of China (52004201), Shaanxi Provincial Natural Science Basic Research Project Enterprise Joint Fund (2019JLZ-04), and the Natural Science Foundation of Shaanxi Provincial Department of Education (20JK0765) for their support of this study.

\section{References}

[1] H. P. Xie, H. W. Zhou, D. J. Xue, H. W. Wang, R. Zhang, and F. Gao, "Research and consideration on deep coal mining and critical mining depth," Journal of China Coal Society, vol. 37, no. 4, pp. 535-542, 2012.

[2] W. X. Dai, W. D. Pan, M. Li, and J. Zhang, "Study on layout and support technology of strongly disturbed roadway in 
contiguous coal seam," Coal Science and Technology, vol. 48, no. 12 , pp. 61-67, 2020.

[3] T. Q. Liu, "The possibility of mining using the upward mining method," Journal of China Coal Society, vol. 1981, no. 1, pp. 18-29, 1981.

[4] L. Q. Wang and Z. H. Li, Technique of Ascending Mining in Coal Seams, Coal Industry Publishing House, Beijing, China, 1995.

[5] J. P. Du and L. Q. Wang, Coal Mine Special Mining Method, China University of Mining and Technology Press, Xuzhou, China, 2003.

[6] J. H. Wang, H. P. Xie, J. Z. Liu et al., "Coal development and utilization theory and technical system of near-zero ecological environment impact," Journal of China Coal Society, vol. 43, no. 5, pp. 1198-1209, 2018.

[7] Y. Zhang and S. G. Cao, "Control of water-flowing fracture development with solid backfill mining: designing a backfill body compression ratio for water resources protection," Mine Water and the Environment, vol. 40, no. 4, pp. 877-890, 2021.

[8] W. L. Shen, G. C. Shi, Y. G. Wang, J. B. Bai, R. F. Zhang, and X. Y. Wang, "Tomography of the dynamic stress coefficient for stress wave prediction in sedimentary rock layer under the mining additional stress," International Journal of Mining Science and Technology, vol. 31, no. 4, pp. 653-663, 2021.

[9] Y. Zhang, Y. Z. Liu, X. P. Lai, and J. M. Gao, "Physical modeling of the controlled water-flowing fracture development during short-wall block backfill mining," Lithosphere, vol. 2021, no. Special 4, article 2860087, 2021.

[10] H. C. Li and M. G. Qian, "A study of ascending mining method at Kongzhuang Mine," Journal of China University of Mining and Technology, vol. 1982, no. 2, pp. 17-29, 1982.

[11] Y. K. Shi and J. Mo, "Numerical analysis of road stress in ascending mining close distance coal seams in deep coal mines," Journal of Mining \& Safety Engineering, vol. 24, no. 4, pp. 473-476, 2007.

[12] L. Q. Ma, L. Q. Wang, D. S. Zhang et al., "Application and study on feasibility of near distancecoal seam group ascending mining," Journal of Hunan University of Science and Technology, vol. 22, no. 4, pp. 1-5, 2007.

[13] G. R. Feng, X. Yan, X. X. Wang Xianxia, L. X. Kang, and Y. D. Zhai, "Determination of key positions of strata controlling in rocks between coal seams for upward mining," Chinese Journal of Rock Mechanics and Engineering, vol. 28, no. 2, pp. 37213726, 2009.

[14] Y. Zhang, C. A. Liu, X. B. Zhang, K. M. Liu, S. K. Zhang, and G. P. Zhao, "The influence of ascending mining on the movement character of overlying coal seam in coal seams group," Journal of China Coal Society, vol. 36, no. 12, pp. 1990-1995, 2011.

[15] Y. Wang, X. Y. Fu, L. H. Kong, Y. Zhao, and N. B. Zhang, "Study on stability of dangling structure in ascending mining contiguous coal seams," Coal Science and Technology, vol. 48, no. 12, pp. 95-100, 2020.

[16] X. X. Miao, "Progress of fully mechanized mining with solid backfilling technology," Journal of China Coal Society, vol. 37, no. 8, pp. 1247-1255, 2012.

[17] J. X. Zhang, J. Li, T. L. An, and Y. L. Huang, "Deformationcharacteristic of key stratum overburden by raw wasterbackfilling with full-mechanized coal mining technology," Journal of China Coal Society, vol. 35, no. 3, pp. 357-362, 2010.
[18] X. J. Deng, Z. X. Yuan, L. X. Lan, B. de Wit, J. W. Zhang, and Q. Chen, "Roof movement and failure behavior when mining extra-thick coal seams using upward slicing longwallroadway cemented backfill technology," Advances in Materials Science and Engineering, vol. 2020, Article ID 5828514, 15 pages, 2020.

[19] Y. J. Zhou, Y. Chen, J. X. Zhang, and Q. He, "Control principle and technology of final compression ratio of backfilling materials," Journal of Mining \& Safety Engineering, vol. 29, no. 3, pp. 351-356, 2012.

[20] Y. Q. Xu, Coal Mining, China University of Mining and Technology Press, Xuzhou, China, 2004.

[21] Y. L. Huang, Ground Control Theory and Application of Solid Dense Backfill in Coal Mines,[Ph.D. Thesis], China University of Mining and Technology, Xuzhou, China, Xuzhou, 2004.

[22] Y. Zhang, S. G. Cao, N. Zhang, and C. Z. Zhao, "The application of short-wall block backfill mining to preserve surface water resources in Northwest China," Journal of Cleaner Production, vol. 261, article 121232, 2020.

[23] M. G. Qian, P. W. Shi, and J. L. Xu, Mining Pressure and Strata Control, China University of Mining and Technology Press, Xuzhou, 2010.

[24] V. Palchik, "Influence of physical characteristics of weak rock mass on height of caved zone over abandoned subsurface coal mines," Environmental Geology, vol. 42, pp. 92-101, 2002.

[25] H. C. Xu, X. P. Lai, S. Zhang et al., "Multiscale intelligent inversion of water-conducting fractured zone in coal mine based on elastic modulus calibration rate response and its application: a case study of Ningdong mining area," Lithosphere, vol. 2021, no. Special 4, article 7657143, 2021.

[26] State Coal Industry Bureau, Regulation of Coal Pillar Retention and Coal Pressing in Buildings, Water Bodies, Railways and Main Tunnels of State Coal Industry Administration, Coal Industry Press, China, Beijing: China, 2000. 